\title{
Traumatic Pseudo Aneurysm of the Inferior Gluteal Artery as a Delayed Complication of a Buttock Penetrating Trauma
}

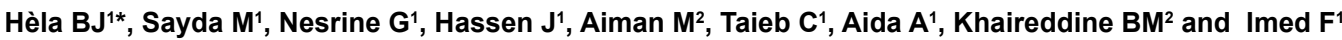

${ }^{1}$ Department of Cardiovascular and Thoracic Surgery, Habib Bourguiba Hospital, Sfax, Tunisia

${ }^{2}$ Department of Radiology, Habib Bourguiba, Sfax, Tunisia

\begin{abstract}
False gluteal aneurysms are exceptional and may develop secondary to penetrating gluteal injury or pelvic trauma. They represent less than $1 \%$ of all aneurysms and they develop within the superior or inferior gluteal arteries, being branches of the internal iliac artery. A case of successfully embolization of a pseudo-aneurysm of the inferior gluteal artery discovered one month after a penetrating buttock trauma is presented. The postoperative course was uneventful, and the pain had resolved completely.
\end{abstract}

Keywords: Inferior gluteal artery; Penetrating trauma; Pseudoaneurysm; Surgery; Embolization

\section{Introduction}

A pseudoaneurysm, also called false aneurysm, occurs due to disruption of one or more layers of the arterial wall. The leaking blood is contained in a perfused sac lined by surrounding tissues [1]. Those of the gluteal arteries are uncommon. They constitute less than $1 \%$ of the all aneurysms [2]. They are due to blunt or penetrating trauma, or pelvic fractures.

The location in the inferior gluteal artery is exceptional. We report a patient with a traumatic gluteal artery false aneurysm diagnosed by a CT scan and successfully thrombosed by selective coil embolization.

\section{Case Presentation}

A thirty-year old man was victim of a penetrating trauma in the right buttock with a puncture wound which was sutured. One month later, he was admitted for a swelling with a severe pain in this region. Physical examination showed a big tumefaction with hematoma and bleeding from the injury, but without pulsating mass (Figure 1). The right femoral and peripheral pulses of the right lower limb were palpable. The patient was pale, anxious, with a pulse rate of 110 beats per minute and a blood pressure of $90 / 60 \mathrm{~mm} \mathrm{Hg}$. The hemoglobin rate was $7 \mathrm{~g} / 100 \mathrm{ml}$, so the patient was transfused with 4 units of blood. A diagnosis of massive arterial hemorrhage, probably from a gluteal artery was suspected. CT scan revealed a huge false aneurysm measuring $2 \mathrm{~cm}$ of diameter of the inferior gluteal artery (Figure 2). The patient underwent angiography, which illustrated the same findings of the CT scan. The aneurysm was successfully embolized with a coil. Femoral access was contralateral. The inferior gluteal artery was cannulated with a probe $5 \mathrm{~F}$ cobra. Embolization was performed on the artery upstream of the aneurysm with establishment of coil 6 and $7 \mathrm{~mm}$. The acquisition of control showed a flow slowdown in the false aneurysm. The postoperative period was uneventful. Color Doppler and CT provided optimal thrombosis and eliminated the need for open surgery (Figure 3 ). The patient was discharged from hospital in the fourth postoperative day.

\section{Discussion}

Internal iliac artery branch pseudo-aneurysms are uncommon, with only a few cases reported in the literature [3].

The superior gluteal artery and internal pudendal arteries are the most commonly involved arteries in pelvic injury [1]. The inferior gluteal artery is rarely involved.

The most frequent causes of pseudo-aneurysms of the gluteal arteries are blunt or penetrating trauma. It can also be iatrogenic after injection of drugs, drainage of an abscess, or surgical debridement of buttock wounds [4]. Pelvic fractures can also damage the inferior gluteal artery or its branches [5]. Mycotic aneurysms have also been reported in the literature [6]. The first symptoms are often pain and swelling in the buttocks, edema, cutaneous erythema, with irritation of the sciatic nerve [2]. A pulsatile mass is palpated. Delay from initial injury to diagnosis of pseudo-aneurysm usually ranges from weeks to months, and rarely exceeds a year [7-9].

One case of false aneurysm of the inferior gluteal artery after a penetrating buttock injury has been reported by Holland et al, as a delayed complication. The patient was treated surgically because embolization had failed [10].

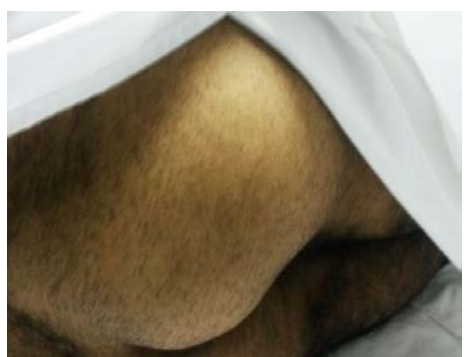

Figure 1: A photography showing a swelling in the right buttock.

*Corresponding author: Hèla BJ, Department of Cardiovascular and Thoracic Surgery, Habib Bourguiba Hospital, Sfax, Tunisia, Tel: +216 74240 341; E-mail: helabenjemaa2015@gmail.com

Received October 18, 2015; Accepted November 10, 2015; Published November 18, 2015

Citation: Hèla BJ, Sayda M, Nesrine G, Hassen J, Aiman M, et al. (2015) Traumatic Pseudo Aneurysm of the Inferior Gluteal Artery as a Delayed Complication of a Buttock Penetrating Trauma. J Vasc Med Surg 3: 231. doi:10.4172/23296925.1000231

Copyright: $\odot 2015$ Hèla BJ, et al. This is an open-access article distributed unde the terms of the Creative Commons Attribution License, which permits unrestricted use, distribution, and reproduction in any medium, provided the original author and source are credited. 
Citation: Hèla BJ, Sayda M, Nesrine G, Hassen J, Aiman M, et al. (2015) Traumatic Pseudo Aneurysm of the Inferior Gluteal Artery as a Delayed Complication of a Buttock Penetrating Trauma. J Vasc Med Surg 3: 231. doi:10.4172/2329-6925.1000231

Page 2 of 3

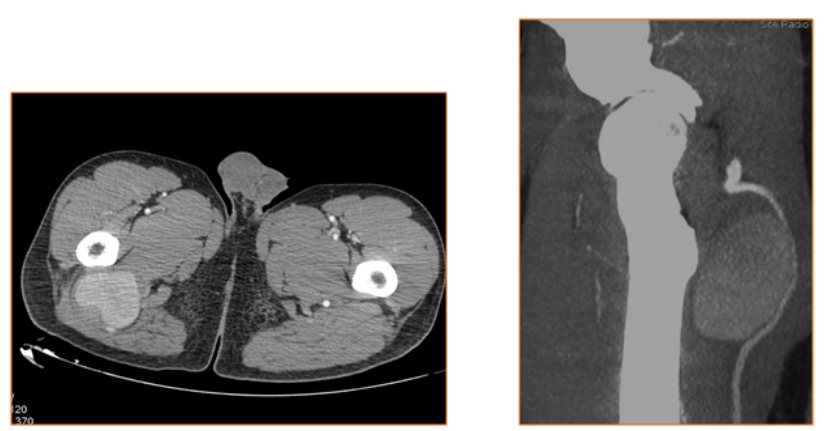

Figure 2: CT scan the false aneurysm (arrow).
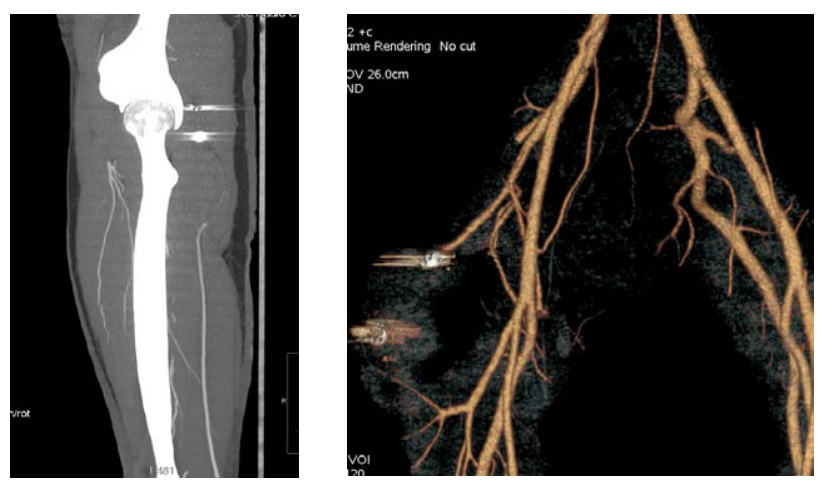

Figure 3: Three-dimensional reconstruction of the CT showing the thrombosis of the pseudo-aneurysm after embolization.

Fanny et al. [11] described a case of post-traumatic inferior gluteal artery pseudoaneurysm diagnosed 37 years after a gunshot injury to the pelvis and successfully treated with trans-catheter embolization. In our case, the diagnosis was made one month after a penetrating trauma, and it was successfully treated with embolization. Duplex scanning allows confirmation of the arterial origin of the mass, whereas the size and topographic relations of aneurysms can better be defined by CT scan which demonstrates a contrast extravasation [12]. The angiography is still mandatory in order to identify, through the selective arteriography of the hypogastric artery, the involved branches. Rupture of pseudoaneurysms is the most severe complication. It has been described first by Lewis [13], and Smith [2].

The treatment of these aneurysmal lesions has been, for a long time, exclusively surgical. In fact, surgical management of the aneurysms was described since the 1700's by John Hunter [14] who used proximal ligation of arteries. Then, Stephens of Vera Cruz demonstrated that ligation of the internal iliac artery has no deleterious consequences [15]. This principle was applied to gluteal aneurysms in 1886 by Dennis [16]. Direct surgical attack on the aneurysm was the method of Antyllus or Anel and consisted of closing the aneurysmal sac from within [17]. Battle [18] in 1898 combined the two principles of proximal control and internal ligation of the sac and this approach has persisted. Surgical control of the iliac arteries can be made by a dual approach: extraperitoneal approach to control and ligate the iliac arteries, and a buttock one to evacuate the blood. Endovascular treatment is currently preferred because its lower morbidity and mortality compared with surgery [19]. There are many endovascular treatment options including stent graft exclusion and embolization. Kocialkowski et al. [20] reported a case of a massive false aneurysm of the gluteal artery following a pelvic fracture, embolized with coils using a crossover technique. Then, a fixation of the fracture was performed through an ilio-inguinal approach.

Selective embolization is considered the treatment of choice; because it has minimal to no complications, and its less exposure and risk for sciatic nerve iatrogenic damage [20,21], whereas direct gluteal surgical intervention has the major risk of severe hemorrhage and trauma to the sciatic nerve [22].

To perform embolization of a false aneurysm, selective hypogastric angiography is mandatory to localize the bleeding vessel [23]. Extravasation is diagnosed on the basis of irregular extravascular collections of high-density contrast. Then, different materials can be used for this purpose; coils of variable diameters and inflatable balloons. Thrombosis of the aneurysmal sac is obtained in the majority of cases [24]. Nevertheless, the major complication of an interventional angiographic approach is failure to control hemorrhage due to the rate of bleeding from extensive injuries. Another complication is an inability to gain adequate access to a bleeding vessel from which embolization may be performed [25]. Management of pseudo aneurysms with stent grafts has also shown encouraging short-term results, although longterm durability has yet to be established.

\section{Conclusion}

Gluteal artery aneurysms are unusual and their clinical presentation is delayed. They must be suspected in patients with gluteal pulsatile masses, and with past history of a penetrating trauma of the gluteal region.

Endovascular treatment by percutaneous selective embolization becomes the preferred method of managing these lesions, because their difficulty to access, and their low morbidity and mortality compared with open surgery.

\section{References}

1. Burli P, Winterbottom AP, Cousins C, Appleton DS, See TC (2008) Imaging appearances and endovascular management of uncommon pseudoaneurysms. Clin Radiol 63: 1254-1264.

2. Smith RB (1981) Spontaneous rupture of a superior gluteal artery aneurysm Injury 12: 343-345.

3. Zhang CW, Yang ZG, Xie XD, Wang CH, You C, et al. (2010) Transcatheter embolization of a ruptured internal pudendal artery pseudoaneurysm in a patient with neurofibromatosis type 1. J Korean Med Sci 25: 638-640.

4. Smyth NP (1968) Gluteal artery rupture. Ann Surg 167: 273-276.

5. Gilroy D, Saadia R, Hide G, Demetriades D (1992) Penetrating injury to the gluteal region. J Trauma 32: 294-297.

6. Benjamin JE, Lachman GS (1924) A case of mycotic aneurysm of the gluteal artery. J A M A 82: 1861-1862.

7. Smyth NP, Rizzoli HV, Ordman CW, Khoury JN, Chiocca JC (1965) Gluteal aneurysm. Arch Surg 91: 1014-1020.

8. Yilmaz AT, Arslan M, Demirkiliç U, Ozal E, Kuralay E, et al. (1997) Missed arterial injuries in military patients. Am J Surg 173: 110-114.

9. Woolgar JD, Reddy DS, Robbs JV (2002) Delayed presentation of traumatic popliteal artery pseudoaneurysms: a review of seven cases. Eur J Vasc Endovasc Surg 23: 255-259.

10. Holland AJ, Ibach EG (1996) False aneurysm of the inferior gluteal artery following penetrating buttock trauma: case report and review of the literature. Cardiovasc Surg 4: 841-843.

11. Fanny SA, Edwards JB, Freitas A, Shafii SM, Rajani RR (2015) Inferior gluteal artery pseudoaneurysm 37 years after transpelvic gunshot wound. Injury, Int $J$ Care Injured 46: 1678-1679. 
Citation: Hèla BJ, Sayda M, Nesrine G, Hassen J, Aiman M, et al. (2015) Traumatic Pseudo Aneurysm of the Inferior Gluteal Artery as a Delayed Complication of a Buttock Penetrating Trauma. J Vasc Med Surg 3: 231. doi:10.4172/2329-6925.1000231

12. Zirinsky K, Markisz JA, Auh YH, Rubenstein WA, Rozenblit G, et al. (1988) Computed tomography and magnetic resonance imaging of a superior gluteal artery pseudoaneurysm. J Comput Tomogr 12: 75-78.

13. Lewis W (1938) Ruptured aneurysm of left gluteal artery with operation. III Med J 73: 331.

14. Zimmerman LM, Veith I (1961) Great Ideas in the History of Surgery. Williams $\&$ Wilkins Co. Baltimore.

15. Haggard WD (1922) Ligation of the internal iliac for enormous gluteal aneurism. Ann Surg 76: 520-527.

16. Dennis FS (1886) Laparotomy in the treatment of spontaneous gluteal and sciatic aneurysms. M News 49: 565 .

17. Meek GN, Hill RL (1968) Surgical treatment of gluteal artery aneurysms. Am J Surg 116: 731-734.

18. Battle WH (1898) A case of traumatic gluteal aneurysm. Byit M J 2: 1415.

19. Saad NE, Saad WE, Davies MG, Waldman DL, Fultz PJ, et al. (2005) Pseudoaneurysms and the role of minimally invasive techniques in their management. Radiographics 25 Suppl 1: S173-189.
20. Kocialkowski A, Colton CL, Gregson RHS (1990) Fracture of the pelvis associated with the gluteal artery false aneurysm. Injury: the British Journal of Accident Surgery 21: 189-190.

21. Mavili E, Donmez H, Ozcan N, Akcali Y (2007) Endovascular treatment of lower limb penetrating arterial traumas. Cardiovasc Intervent Radiol 30: 1124-1129.

22. Goktay AY, Secil M, Dicle O, Pirnar T (2001) Color doppler sonography in the follow-up of giant glutealaneurysm embolization. Computerized Medical Imaging and Graphics 25: 353-356.

23. Panetta T, Sclafani SJ, Goldstein AS (1985) Percutaneous transcatheter embolization for massive bleeding from pelvic fractures. J Trauma 25: 10211029.

24. Vasseur MA, Doisy VC, Prat AG, Stankowiak C (1998) Coil embolization of a gluteal false aneurysm in a patient with Marfan syndrome. J Vasc Surg 27: 177-179.

25. Bassam D, Cephas GA, Ferguson KA, Beard LN, Young JS (1998) A protocol for the initial management of unstable pelvic fractures. Am Surg 64: 862-867. 